This document is confidential and is proprietary to the American Chemical Society and its authors. Do not copy or disclose without written permission. If you have received this item in error, notify the sender and delete all copies.

\title{
Homeopathic Perovskite Solar Cells: Effect of Humidity During Fabrication on the Performance and Stability of the Device
}

\begin{tabular}{|r|l|}
\hline Journal: & The Journal of Physical Chemistry \\
\hline Manuscript ID & Draft \\
\hline Manuscript Type: & Article \\
\hline Date Submitted by the Author: & n/a \\
\hline Complete List of Authors: & $\begin{array}{l}\text { Contreras Bernal, Lidia; Universidad Pablo de Olavide, Department of } \\
\text { Physical, Chemical and Natural Systems, Nanostructured Solar Cells Group } \\
\text { Aranda, Clara; Universitat Jaume I } \\
\text { Valles-Pelarda, Marta; Universitat Jaume I, Physics } \\
\text { Ngo, Thi Tuyen; Universitat Jaume I, Physics } \\
\text { Ramos-Terrón, Susana; Universidad Pablo de Olavide, Department of } \\
\text { Physical, Chemical and Natural Systems, Nanostructured Solar Cells Group } \\
\text { Gallardo, Juan; Universidad de Cádiz, Química Física } \\
\text { Navas, Javier; Universidad de Cadiz, Química Física } \\
\text { Guerrero, Antonio; Universidad Jaume I, } \\
\text { Mora-Sero, Ivan; Universitat Jaume I, Physics } \\
\text { Idigoras, Jesus; Universidad Pablo de Olavide, } \\
\text { Anta, Juan; Universidad Pablo de Olavide, Area de Química Física, Sistemas } \\
\text { Físicos, Químicos y Naturales }\end{array}$ \\
\hline
\end{tabular}



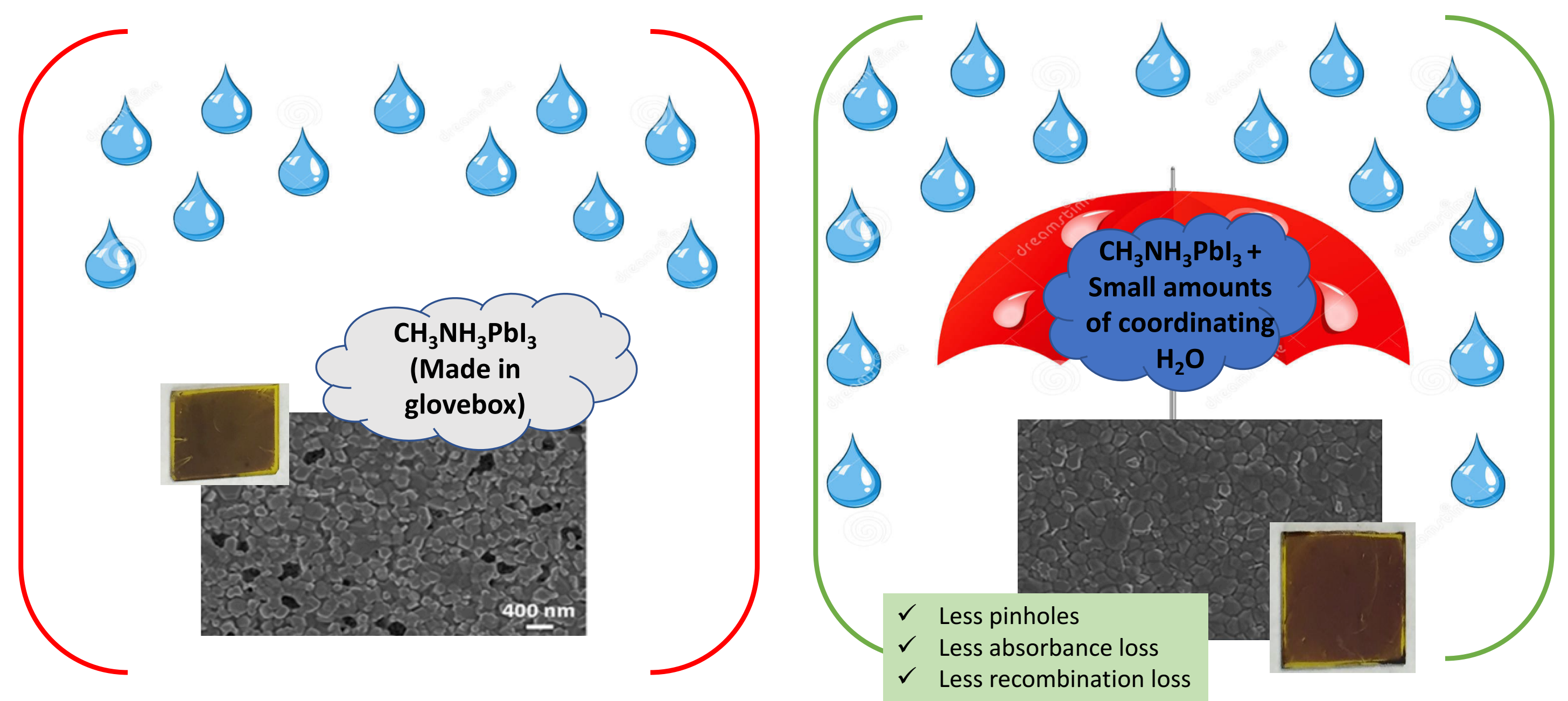


\title{
Homeopathic perovskite solar cells: Effect of humidity during fabrication on the performance and stability of the device
}

\author{
Lidia Contreras-Bernal ${ }^{\mathrm{a}}$, Clara Aranda, ${ }^{\mathrm{b}}$ Marta Valles-Pelarda, ${ }^{\mathrm{b}}$ Thi Tuyen Ngo, ${ }^{\mathrm{b}}$ Susana Ramos-Terrón ${ }^{\mathrm{a}}$, \\ Juan Jesús Gallardo, ${ }^{\mathrm{c}}$ Javier Navas, ${ }^{\mathrm{c}}$ Antonio Guerrero, Iván Mora-Seró*, Jesús Idígoras ${ }^{\mathrm{a}, *}$, Juan A. \\ Anta $^{\mathrm{a}, *}$ \\ a'́rea de Química Física, Universidad Pablo de Olavide, E-41013, Sevilla, Spain \\ ${ }^{\mathrm{b}}$ Institute of Advanced Materials (INAM), Universitat Jaume I, E-12006 Castelló, Spain \\ ${ }^{\mathrm{c}}$ Departamento de Química Física, Facultad de Ciencias, Universidad de Cádiz, E-11510 Puerto Real \\ (Cádiz), Spain
}

\begin{abstract}
Methylammonium Lead Iodide $\left(\mathrm{CH}_{3} \mathrm{NH}_{3} \mathrm{PbI}_{3}\right)$ is the archetypical active component of perovskite solar cells, which stand out due to their impressive photovoltaic performance. A major drawback of $\mathrm{CH}_{3} \mathrm{NH}_{3} \mathrm{PbI}_{3}$ is its rapid degradation in humid environments. In this work, we fabricate $\mathrm{CH}_{3} \mathrm{NH}_{3} \mathrm{PbI}_{3}$ films and devices by solvent engineering in $\mathrm{N}_{2}$ and in ambient conditions with different humidities. Their aging and degradation is monitored by optical absorption and impedance spectroscopy measurements under monochromatic illumination with two different wavelengths. Aged devices show a substantial difference between the recombination rate under red and blue light illumination, attributed to enhancement of local recombination routes upon aging. Interestingly, we observe that devices prepared at higher humidity resist better the aging. We explain this by the presence of coordinating water in the films, as detected by XPS measurements. Hence, small amounts of water in the perovskite structure proves to have a beneficial effect against degradation in humid environments.
\end{abstract}




\section{INTRODUCTION}

Progress in third generation photovoltaics has experienced a remarkable boost in recent years due to the discovery of the exceptional optoelectronic and photovoltaic properties of halide perovskites. This new kind of photovoltaic materials made it possible to reach certified efficiencies above $22 \%$ in just a time span of a few years. ${ }^{1}$ Halide perovskites are a family of ionic solids where $\mathrm{CH}_{3} \mathrm{NH}_{3} \mathrm{PbI}_{3}$ is the most archetypical example, providing a high performance due to a near-optimal light-harvesting direct band gap (close to $1.5 \mathrm{eV}$ ) and very low nonradiative recombination rates leading to high open-circuit voltages. ${ }^{2-5}$

Despite these favourable features, it was soon realized that perovskite solar cells (PSC) suffer from serious stability issues. These materials tend to easily degrade in the presence of light, heat, oxygen and/or moisture. ${ }^{6,7}$ In this work we focus on moisture-induced aging. The mechanism by which water molecules induce the destruction of the perovskite material is not completely clarified yet but there are indications ${ }^{8}$ that it takes place via the formation of an intermediate hydrate

$$
4 \mathrm{CH}_{3} \mathrm{NH}_{3} \mathrm{PbI}_{3}+4 \mathrm{H}_{2} \mathrm{O} \leftrightarrow 4\left[\mathrm{CH}_{3} \mathrm{NH}_{3} \mathrm{PbI}_{3} \bullet \mathrm{H}_{2} \mathrm{O}\right] \leftrightarrow\left(\mathrm{CH}_{3} \mathrm{NH}_{3}\right)_{4} \mathrm{PbI}_{6} \bullet 2 \mathrm{H}_{2} \mathrm{O}+3 \mathrm{PbI}_{2}+2 \mathrm{H}_{2} \mathrm{O}
$$

The effect of moisture in $\mathrm{CH}_{3} \mathrm{NH}_{3} \mathrm{PbI}_{3}$ is easily detected by absorbance measurements ${ }^{9}$ and even with the naked eye when the brownish perovskite film becomes yellow due to the formation of $\mathrm{PbI}_{2}$.

The critical point of the mechanism for sample degradation is that very few molecules of water are sufficient to trigger the process. As a Lewis base, $\mathrm{H}_{2} \mathrm{O}$ can coordinate with the ammonium groups. The hydrates which are formed ${ }^{8,10}$ can appear locally and modify the electronic properties of the material, even when no defect can be visually detected.

Very recently ${ }^{11}$ we have shown that this donor property of the water molecules with the ammonium groups can be taken advantageously to devise a preparation procedure at ambient conditions with relative humidity (R.H.) up to $60 \%$. By controlling the proportion of the dimethyl sulfoxide (DMSO) additive with respect to the $\mathrm{Pb}^{2+}$ as a function of the R.H. of the ambient atmosphere it is possible to fabricate highly homogenous films at ambient conditions and solar cells devices with efficiencies approaching 19\%. Using precursors formulations in which the two competing donors DMSO and ambient $\mathrm{H}_{2} \mathrm{O}$ are not adequately balanced leads to the formation of chemical defects (plumbates, hydrates) that can act as recombination centers.

Although most previous studies on moisture-induced degradation focused on materials properties and monitored the degradation process via optical and X-ray measurements, ${ }^{8,9,12}$ it is known that ambient water produces changes in the electrical properties of the films but few analysis in this line have been reported in the literature. We previously studied the change in the optoelectronic 
small-perturbation response of perovskite devices upon aging, ${ }^{13}$ showing a change of the recombination mechanism and slower transport in degraded devices by small perturbation optoelectronics measurements. This effect is attributed to a global acceleration of recombination and/or the appearance of additional surface recombination processes. ${ }^{14,15}$

In this work, we investigate the mechanisms and kinetics of moisture-induced aging and degradation of $\mathrm{CH}_{3} \mathrm{NH}_{3} \mathrm{PbI}_{3}$ perovskite solar cells fabricated at ambient conditions where humidity is perfectly controlled. We found that the fabricated films and devices are quite robust in the medium term stressed under high R.H. conditions. Furthermore, it is observed that devices prepared in a more humid environment tend to keep their electric original properties better than those prepared at lower moisture conditions.

\section{EXPERIMENTAL METHODS}

\section{Fabrication of perovskite solar cells}

Perovskite solar cells were fabricated on FTO-coated glass (Pilkington-TEC15) patterned by laser etching. The substrates were cleaned using Hellmanex ${ }^{\circledR}$ solution and rinsed with deionized water and ethanol. Followed this they were sonicated in 2-propanol and dried by using compressed air. The $\mathrm{TiO}_{2}$ blocking layer was deposited onto the substrates by spray pyrolysis at $450{ }^{\circ} \mathrm{C}$, using a titanium diisopropoxide bis(acetylacetonate) solution (75\% in 2-propanol, Sigma Aldrich) diluted in ethanol $(1: 3.5, \mathrm{v} / \mathrm{v})$, with oxygen as carrier gas. The $\mathrm{TiO}_{2}$ compact layer was then kept at $450{ }^{\circ} \mathrm{C}$ for $30 \mathrm{~min}$ for the formation of anatase phase. Once the samples achieve room temperature, a $\mathrm{TiO}_{2}$ mesoporous layer was deposited by spin coating at $2000 \mathrm{rpm}$ during 10 s using a $\mathrm{TiO}_{2}$ paste (Dyesol, 30NRD) diluted in ethanol (1:5, weight ratio). After drying at 100 ${ }^{\circ} \mathrm{C}$ for $10 \mathrm{~min}$, the $\mathrm{TiO}_{2}$ mesoporous layer was heated at $500{ }^{\circ} \mathrm{C}$ for $30 \mathrm{~min}$ and later cooled to room temperature. Subsequently, a pure methylammonium lead iodide $\left(\mathrm{CH}_{3} \mathrm{NH}_{3} \mathrm{PbI}_{3}\right)$ solution were prepared to be deposited by spin coating.

The perovskite precursor solution is obtained from reacting DMF solutions (50 wt \%) containing MAI and PbI2 (1:1 mol \%) and MAI, PbI2 and DMSO (1:1:1 mol \%) and for the different humidity values of $50 \%, 40 \%, 30 \%$ and $0 \%$ (this latter in glovebox), the molar ratio of DMSO was changed from $0.75 ; 1 ; 1 ; 1.5$, respectively. The perovskite precursor solution $(50 \mu \mathrm{L})$ was spin-coated in a one-step setup at $4000 \mathrm{rpm}$ for $50 \mathrm{~s}$. During this step, DMF is selectively washed with non-polar diethyl ether just before the white solid begins to crystallize in the substrate. Afterward the substrate was annealed at $100{ }^{\circ} \mathrm{C}$ for $3 \mathrm{~min}$ (see Ref. ${ }^{11}$ for details)

For the sake of comparison, reference perovskite films fabricated with a standard recipe ${ }^{13}$ inside a glovebox ( $0 \%$ R.H) were also included in the study: Pure methylammonium lead iodide (1.2 M) was spin coated in a two steps setup at 1000 and $6000 \mathrm{rpm}$ for 10 and 20s respectively. During the second step, $110 \mu \mathrm{L}$ of chlorobenzene was dropped on the spinning substrate 15 seconds before the end of the spinning program. The samples were then annealed $\left(100^{\circ} \mathrm{C}\right)$ for $1 \mathrm{~h}$ in an argon filled glove box. 
Spiro-OMeTAD was deposited as hole transporting material (HTM) by dissolving $72.3 \mathrm{mg}$ in 1 $\mathrm{mL}$ of chlorobenzene as well as $17.5 \mu \mathrm{L}$ of a lithium bis (trifluoromethylsulphonyl)imide (LiTFSI) stock solution ( $520 \mathrm{mg}$ of LiTFSI in $1 \mathrm{~mL}$ of acetonitrile), and $28.8 \mu \mathrm{L}$ of 4-tertbutylpyridine (TBP). The HTM was spin coated at $4000 \mathrm{rpm}$ for $30 \mathrm{~s}$. Finally, $60 \mathrm{~nm}$ of gold was deposited as a metallic contact by thermal evaporation under a vacuum level between $1 \cdot 10^{-6}$ and $1 \cdot 10^{-5}$ torr. All the deposition processes were carried out outside the glovebox under different humidity conditions. Only for humidity conditions of $0 \%$ relative humidity $(\mathrm{RH})$ the devices were prepared inside an argon glove box under controlled moisture and oxygen conditions $\left(\mathrm{H}_{2} \mathrm{O}\right.$ level: $<1 \mathrm{ppm}$ and $\mathrm{O}_{2}$ level: $\left.<10 \mathrm{ppm}\right)$.

Aging was studied by subjecting perovskites solar devices prepared under different moisture conditions (RH: $0 \%, 30 \% 40 \%$ and 50\%) to ambient air in darkness during 15 days under environmental moisture conditions with a relative humidity in the range of $30 \%-60 \%$. In addition, perovskite films deposited on the $\mathrm{TiO}_{2}$ substrate were subjected to an accelerating degradation treatment by exposing the film to very humid air $(>85 \%)$ for a relatively long period of time.

\section{Characterization of films and devices}

Current density-voltage (J-V) curves were measured under a solar simulator (ABET-Sun2000) with an AM $1.5 \mathrm{G}$ filter. The light intensity was calibrated at $100 \mathrm{mWcm}^{-2}$ using a reference mono-crystalline silicon solar cell with temperature output (ORIEL, 91150). A metal mask was used to define an active area of $0.16 \mathrm{~cm}^{2}$. The current-voltage curves were obtained using a scan rate of $100 \mathrm{mV} / \mathrm{s}$ and sweep delay of $20 \mathrm{~s}$.

The illumination for the Impedance Spectroscopy (IS) measurements was provided by a red $(\lambda=$ $635 \mathrm{~nm})$ and blue $(\lambda=465 \mathrm{~nm})$ LEDs over a wide range of DC light intensities. This allows for probing the devices with two distinct optical penetrations. ${ }^{14}$ A response analyzer module ((PGSTAT302N/FRA2, Autolab) was utilized to register the impedance spectra. In these experiments a $20 \mathrm{mV}$ perturbation in the $10^{6}-10^{-2} \mathrm{~Hz}$ range was applied. To avoid voltage drop due to series resistance, the measurements were performed at the open circuit potential, the Fermi level (related to the open-circuit voltage) being fixed by the DC (bias) illumination intensity. To compensate for the different response under blue and red light due to the different optical absorption all parameters are monitored and plotted as a function of the open-circuit potential generated by each type of bias light. UV-Visible absorption spectra were recorded by using a Cary $100 \mathrm{UV}-\mathrm{Vis}$ spectrophotometer (Agilent) in the range of 400-850 nm.

X-ray photoelectron spectroscopy (XPS) was used to analyse the chemical composition and the presence of water in the samples. The XPS spectra were recorded using a Kratos Axis UltraDLD spectrometer, with monochromatized $\mathrm{Al} \mathrm{K \alpha}$ radiation $(1486.6 \mathrm{eV}), 20 \mathrm{eV}$ pass energy and an accuracy of $0.1 \mathrm{eV}$. Electrostatic charging effects could be stabilized with the help of a specific device developed by Kratos. 


\section{RESULTS AND DISCUSSION}

The photovoltaic parameters of fresh and aged devices are compared in Figure S1 and Table 1. Devices are aged by subjecting devices to ambient air at R.H. $=30-60 \%$ humidity in darkness during 15 days, similar to the ISOS-D1-shelftest protocol where the humidity is controlled. ${ }^{16}$ Fresh devices show an almost constant average energy conversion efficiency of around 14\% (see Table 1). After aging, this efficiency is reduced by $1 \%$ for the devices fabricated in dry conditions. In contrast, the devices made under the highest humidity (50\%) get their efficiencies even increased, with recorded values well exceeding $15 \%$. It is observed that the efficiency loss is mainly due to a deterioration of the fill factor of the devices. The efficiency boost is, though, linked to an enhancement of the short-circuit photocurrent. This effect can be related to the increase of the optical absorbance of the $\mathrm{CH}_{3} \mathrm{NH}_{3} \mathrm{PbI}_{3}$ upon accelerated degradation as shown and discussed in the Supporting Information (section S2). The open-circuit potential remains basically unaltered after aging although a slight decrease can be detected.

Table 1. Photovoltaic parameters under AM1.5 1 sun illumination of fresh (top) and aged (bottom) $\mathrm{MAPbI}_{3}$ solar cells fabricated under humid conditions. Error bars extracted from the statistics extracted from the measurements of 3-5 devices are added to the data.

\begin{tabular}{ccccc} 
R.H (\%) & $\mathbf{J}_{\mathbf{s c}}\left(\mathbf{A} \cdot \mathbf{c m}^{-\mathbf{2}}\right)$ & $\mathbf{V}_{\mathbf{O C}}(\mathbf{V})$ & $\mathbf{F F}(\mathbf{\%})$ & $\mathbf{E F F}(\mathbf{\%})$ \\
\hline \hline & & FRESH & & \\
0 & $19.70 \pm 0.88$ & $1.05 \pm 0.01$ & $69.0 \pm 0.6$ & $14.4 \pm 0.7$ \\
30 & $21.20 \pm 0.52$ & $1.01 \pm 0.02$ & $65.3 \pm 1.9$ & $14.0 \pm 0.6$ \\
40 & $20.63 \pm 1.41$ & $1.04 \pm 0.01$ & $66.2 \pm 6.5$ & $14.2 \pm 0.8$ \\
50 & $20.53 \pm 0.35$ & $1.04 \pm 0.01$ & $66.6 \pm 1.6$ & $14.2 \pm 0.3$ \\
& & & & \\
& & AGED & & \\
30 & $20.62 \pm 0.18$ & $1.04 \pm 0.08$ & $61.0 \pm 4.7$ & $13.1 \pm 1.3$ \\
40 & $22.13 \pm 0.89$ & $0.96 \pm 0.02$ & $62.0 \pm 3.3$ & $13.4 \pm 0.5$ \\
50 & $23.36 \pm 0.81$ & $0.95 \pm 0.03$ & $63.0 \pm 4.0$ & $14.1 \pm 1.0$ \\
& $24.53 \pm 0.52$ & $1.01 \pm 0.06$ & $62.2 \pm 3.3$ & $15.4 \pm 0.5$
\end{tabular}

In Figure 1 a comparison between the absorbance degradation kinetics of samples prepared under dry and high humidity conditions is depicted when stressed with humid air. ${ }^{13}$ The absorption spectrum of a perovskite film prepared under very high humidity conditions (R.H. 50\%) remains basically unaltered after being vented in very humid air ( $>85 \%$ R.H.) up to 8 hours. Additional exposure to ambient conditions for 18 additional hours $(\approx 50 \% \mathrm{RH})$ even led to a slight increase of the absorbance at short wavelengths. This increase in absorbance has been correlated 
previously with a decrease of under-coordinated plumbate ions. ${ }^{17}$ In contrast, the films prepared in the glovebox showed a dramatic decrease of the absorbance, especially after 25 hours. This result confirms the exceptional stability of the films formed under humid conditions towards moisture-induce degradation.

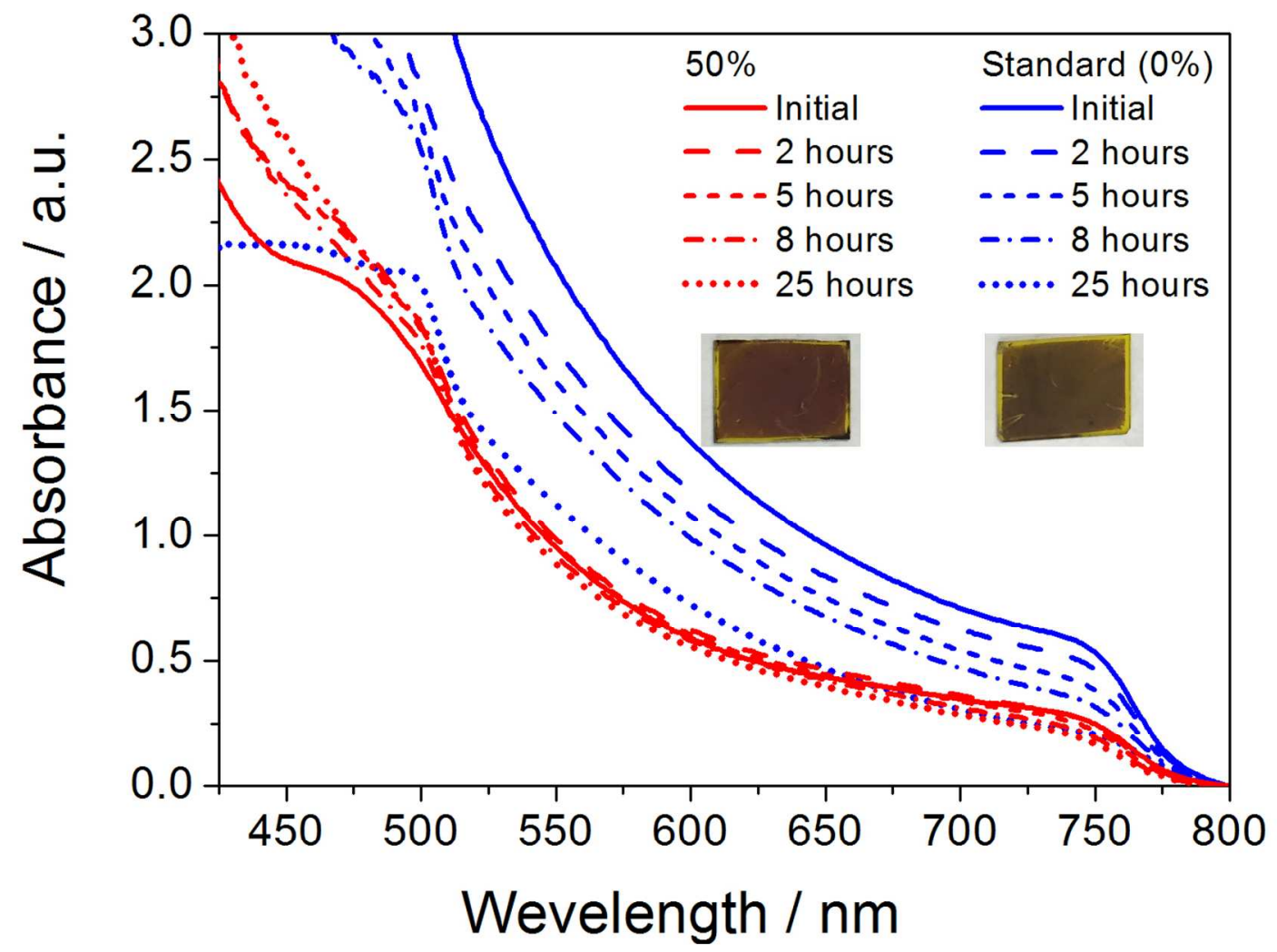

Figure 1. Optical absorption data of bare $\mathrm{MAPbI}_{3}$ films deposited on $\mathrm{TiO}_{2}$ substrates by solventengineering under 50\% R.H. (homeopathic) and by reference (standard) recipe at dry conditions. ${ }^{13}$ Between 0 and 8 hours the films were subject to a flow of humid air $(>85 \% \mathrm{RH})$. Between 8 and 25 hours the films were left exposed to the ambient atmosphere at an approximate $50 \%$ R.H. Photographs of the two films after the degradation treatment are also added to the picture. Note that the two recipes do not produce the same film thickness, hence the different initial absorption.

The stability of the perovskite films after moisture exposure can also be studied by SEM images of fresh and degraded films fabricated at three different humidity conditions: $30 \%, 40 \%$ and $50 \%$ (Figure 2). The used recipe produces homogeneous films with no pinholes and an approximately constant crystal size of around $200 \mathrm{~nm}$. Degradation upon exposure to humid air (>85\% R.H.) show up in the form of inhomogeneities and pinholes. An increase of the grain size is also observed. $^{18}$ These features appear to be less important for films fabricated at higher humidity $(50 \% \mathrm{RH})$ than those made at lower values of humidity $(30 \%$ R.H.). On the other hand, as mentioned, ambient water promotes increased crystalline domains from about $100 \mathrm{~nm}$ for the reference device to up to 500-600 $\mathrm{nm}$. This observation can be explained by the action of ambient 
water, which acts an additive that can promote Ostwald ripening effect and increasing the domain size as recently reported with Guanidinium Thiocyanate. ${ }^{19}$

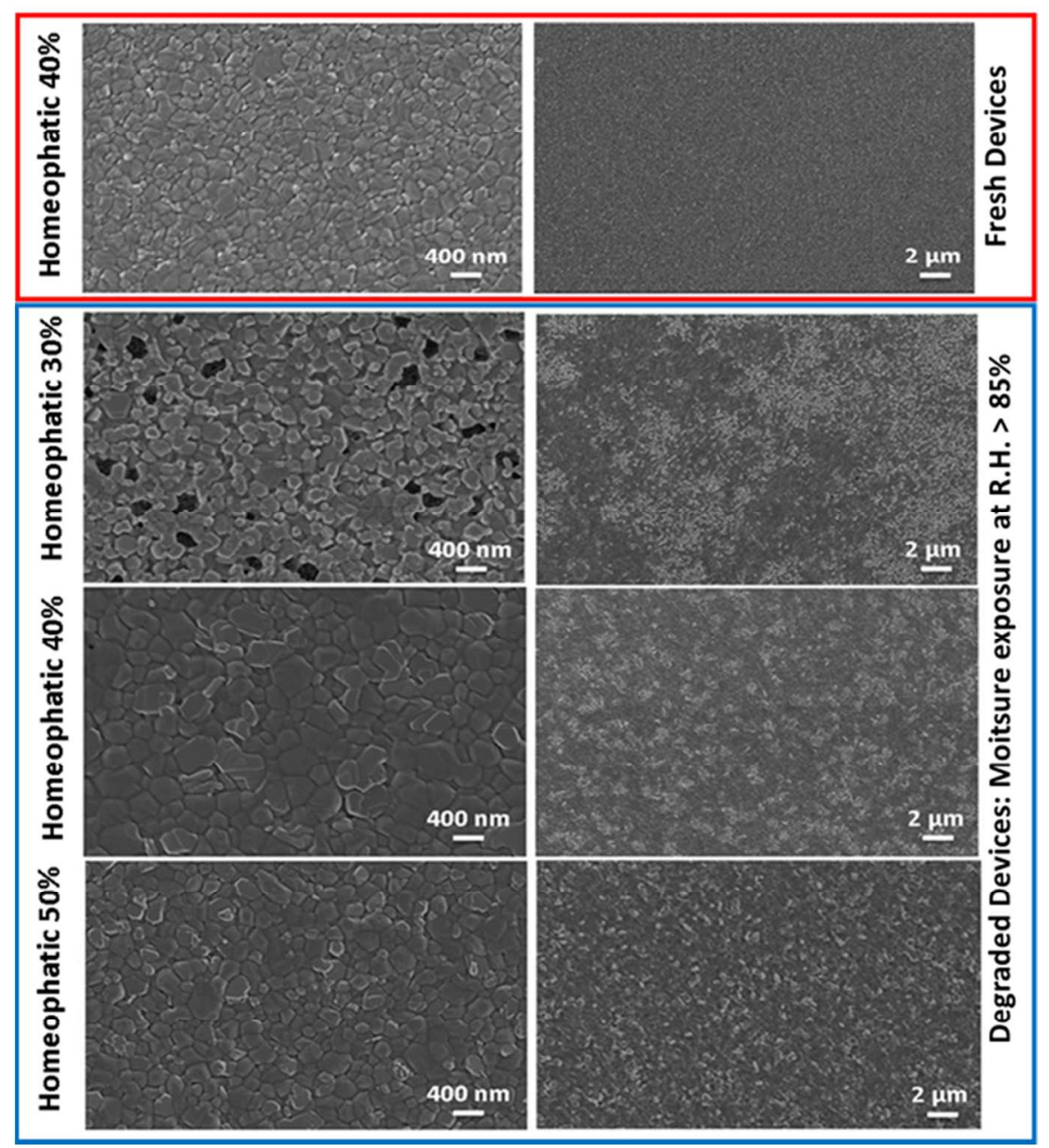

Figure 2. SEM images of fresh perovskite films fabricated at R.H. $=40 \%$ (top) and after degradation (bottom). Results for degraded films with very humid air (>85\% R.H.) but prepared at different ambient humidity values are shown.

The robustness of the films fabricated under ambient conditions suggests that these films retain some water molecules in the crystalline structure, thus preventing further invasion by moisture. To test this hypothesis XPS measurements were performed for samples exposed at different relative humidity, that is $0 \%, 30 \%, 40 \%$ and $50 \%$. Figure S3 in the Supporting Information shows the survey spectra for the samples. The peaks are assigned to the elements which composed the perovskite phase, that is $\mathrm{C}, \mathrm{N}, \mathrm{Pb}$ and $\mathrm{I}$. In turn, no evidence of Ti is observed, which confirms that only the perovskite layer is analysed. However, a weak $\mathrm{O} 1 \mathrm{~s}$ signal, produced by small amounts of water in the perovskite structure, can be detected. Figures S4 and 3a show the O 1s signal obtained for the samples. The binding energy (BE) for $\mathrm{O} 1 \mathrm{~s}$ signal for the four samples is about $531.5 \mathrm{eV}$. As reported previously, the presence of coordinating (hydrating) water appears 
in the range between $531.0-531.6 \mathrm{eV} .{ }^{20}$ This signal at $\mathrm{BE}$ of $531.5 \mathrm{eV}$ cannot be assigned to $\mathrm{O}^{2-}$ in the lattice of oxide species as this type of signal is typically observed at BE lower than $530 \mathrm{eV}$. For instance, in the case of lead oxides, they appear between 528.4 and $529.4 \mathrm{eV} .{ }^{21}$ Other typical assignation for $\mathrm{O} 1 \mathrm{~s}$ signal is to adsorbed species, such as water, hydroxyl groups or carboxylates species, but these contributions normally show up at BE higher than $532 \mathrm{eV}^{22-24}$ On the other hand, Figure $3 \mathrm{~b}$ shows the $\mathrm{Pb} 4 \mathrm{f}$ signal for the sample exposed to $50 \% \mathrm{RH}$, which is considered

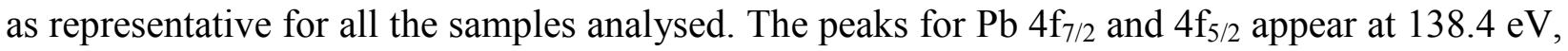
and $143.3 \mathrm{eV}$, respectively. The $4.9 \mathrm{eV}$ separation between this spin-orbit components is typical for $\mathrm{Pb}(\mathrm{II}){ }^{20}$ Figure $3 \mathrm{~b}$ also includes a deconvolution of the $\mathrm{Pb} 4 \mathrm{f}_{7 / 2}$ signal. Two contributions can be extracted. The main contribution (peak 1) at a $\mathrm{BE}$ of $138.4 \mathrm{eV}$ is assigned usually ${ }^{20}$ to $\mathrm{PbI}_{2}$. This is the contribution from the $\mathrm{Pb}$-I bonds of the perovskite. The small contribution (peak 2) appears at about $137.4 \mathrm{eV}$. The signals around this value of $\mathrm{BE}$ for $\mathrm{Pb}_{4} \mathrm{f}_{7 / 2}$ are usually ascribed to species in which $\mathrm{Pb}-\mathrm{O}$ interactions are present.

Therefore, for XPS measurements, the presence of coordinating water can be deduced from the energy position of the $\mathrm{O} 1 \mathrm{~s}$ signal and it is confirmed with the analysis of the $\mathrm{Pb} 4 \mathrm{f}$ signal. Although a signal is observed in the $0 \%$ sample (probably due to residual water during sample manipulation before measurement), it is significantly smaller than the signal obtained for the $50 \%$ film. Nevertheless, due to the low intensity of the signal, the evolution of the water content with respect to the relative humidity (Figure S4) cannot be safely monitored from these measurements. In any case, the presence of coordinating water molecules around the $\mathrm{Pb}$ cations explain the molecular stability of the perovskite films towards inclusion of additional water during aging or degradation experiments.
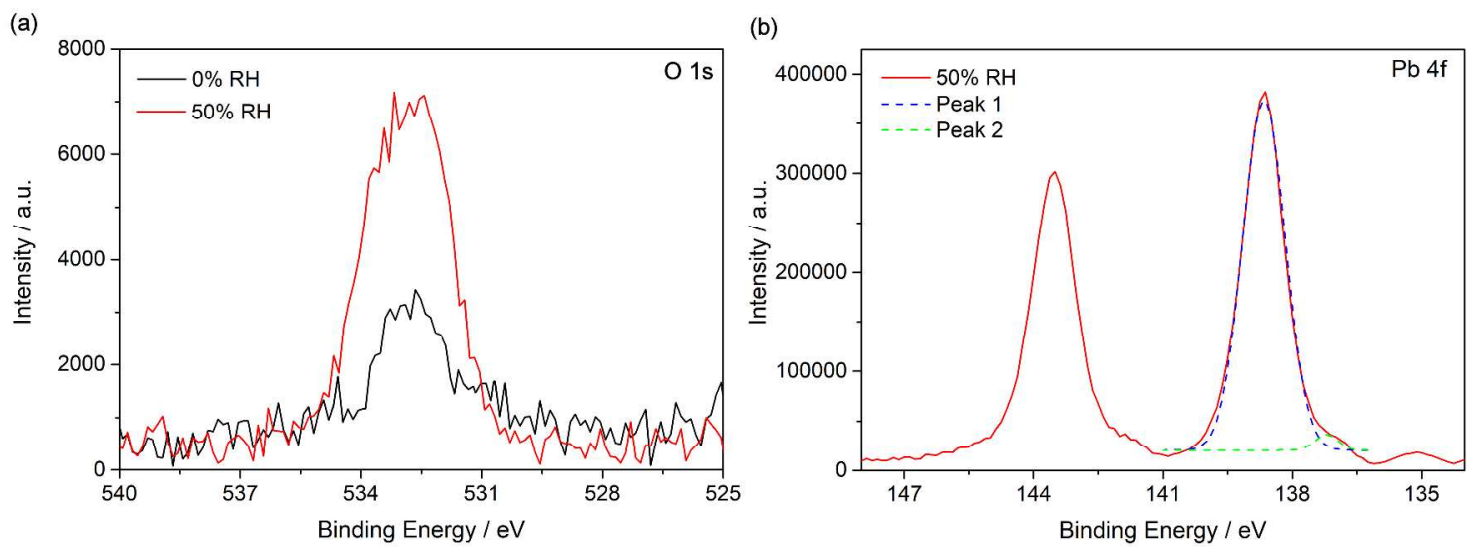

Figure 3. $\mathrm{O} 1 \mathrm{~s}$ and $\mathrm{Pb} 4 \mathrm{f}$ signals obtained from XPS measurements of perovskite thin films deposited on top of mesoporous $\mathrm{TiO}_{2}$ layers fabricated at different ambient humidity values.

Finally, to verify the change in the internal functioning of the perovskite solar cell upon aging, impedance spectroscopy (IS) measurements at open circuit were carried out. This technique allows to discriminate between electronic processes occurring at separated frequencies (defining 
consequently different characteristic time constants). The IS response of perovskite solar cells is typically characterized by the appearance of two signals, visualized as peaks in the frequency plots (either phase vs. frequency or imaginary impedance vs. frequency) or arcs in the Nyquist plot. Although both signals are found to be coupled ${ }^{25,26}$ it is generally accepted that the low frequency (LF) signal is related to ion migration affecting charge accumulation at the contacts ${ }^{27-}$ ${ }^{29}$, whereas the high-frequency (HF) signal is affected by the transport in the selective contacts and interfaces. ${ }^{27,30}$ However the assignation of each feature observed by impedance to a single process is not correct as high and low frequency features change mutually and both arcs can be related with recombination ${ }^{26,31-33}$ Consequently the analysis of the evolution of these arcs can be inversely related with the recombination rate. In this work, we focus in the HF region, in the $10^{3}$ $10^{6}$ range. The measurements were carried out with two excitation wavelengths, characterized by a different penetration of the light into the perovskite layer. ${ }^{29}$

The HF resistance has been extracted from the impedance spectra by fitting the data to a simple Voight circuit, composed of two RC elements in series plus a series resistance term. ${ }^{34}$ The corresponding high frequency resistance $R_{H F}$ is plotted in Figure 4 as a function of the opencircuit potential, originated by the different illumination intensities applied, and the two excitation wavelengths employed in the experiment.
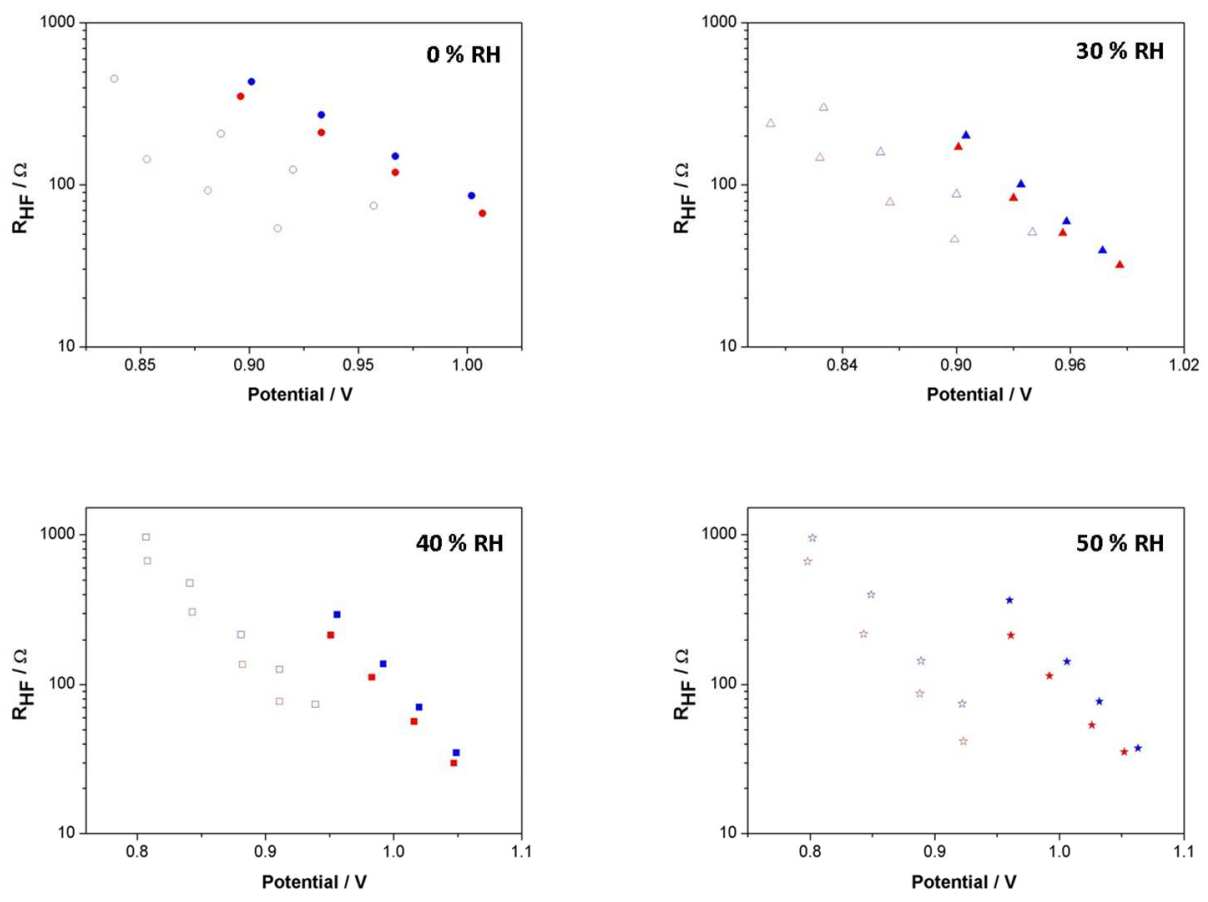

Figure 4. High frequency resistance versus open-circuit potential for devices prepared under different humidity conditions, as indicated. Red and blue symbols stand for the data extracted under red and blue light illumination, respectively. Solid symbols correspond to fresh devices and open symbols to aged devices. 
$\mathrm{R}_{\mathrm{HF}}$ is found to vary exponentially with the open circuit potential as predicted by the following equation $^{14,15}$

$$
R_{H F}=\left(\frac{\partial J_{r e c}}{\partial V}\right)^{-1}=R_{00} \exp \left(\frac{-\beta q V}{k_{B} T}\right)
$$

where $J_{\text {rec }}$ is the recombination current, $k_{B}$ is the Boltzmann constant, $T$ is the absolute temperature, $R_{00}$ is the resistance at zero potential and $\beta$ is the transfer or recombination parameter. We have previously found that this parameter is the inverse of the ideality factor $m=$ $1 / \beta$ and coincides with that extracted from the slope of the open-circuit potential vs. light intensity plot. ${ }^{14}$ In Table 2 ideality factors extracted from the solar cells studied in this work are reported.

Table 2. Ideality factors for fresh and degraded cells as extracted from the high frequency resistances in Figure 4

\begin{tabular}{ccccc} 
& \multicolumn{4}{c}{ Ideality factor } \\
R.H. ( \%) & \multicolumn{2}{c}{ Fresh cell } & Degraded cell \\
\cline { 2 - 5 } & Blue & Red & Blue & Red \\
\hline \hline 0 & $2.38 \pm 0.01$ & $2.44 \pm 0.02$ & $2.94 \pm 0.08$ & $2.78 \pm 0.08$ \\
30 & $1.75 \pm 0.01$ & $1.85 \pm 0.09$ & $2.44 \pm 0.01$ & $2.50 \pm 0.06$ \\
40 & $1.69 \pm 0.01$ & $1.85 \pm 0.01$ & $1.92 \pm 0.06$ & $1.96 \pm 0.06$ \\
50 & $2.08 \pm 0.06$ & $2.08 \pm 0.14$ & $1.75 \pm 0.05$ & $1.75 \pm 0.01$
\end{tabular}

The analysis of the ideality factors reveal that they are approximately the same for both blue and red light illumination, and with values close to 2, which can be attributed to bulk SRH recombination. ${ }^{14,35-37}$ However, there is a clear net enhancement in the recombination rate after degradation, as evidenced by the lower values of $R_{H F}$ in Figure 4 . This result is in line with reduction of the open-circuit potential at 1 sun illumination reported in Table 1, and it indicates that the inclusion of ambient water into the perovskite structure introduces recombination centers and additional routes of non-radiative recombination. Furthermore, the degraded devices exhibit a different value of the recombination resistance depending on whether red or blue light is used to generate the open-circuit potential. Red light illumination produces photo-generated carriers further away from the $\mathrm{TiO}_{2}$ /perovskite interphase in comparison with blue light due to the lower light absorption in the red. Lower values of $R_{H F}$ are observed under red light illumination in all aged devices. This fact can be interpreted as (1) a magnification of the recombination loss close to the perovskite/hole transport material interface and/or (2) a global acceleration of the bulk recombination rate, leading to shorter diffusion lengths. ${ }^{14}$

An important property also arises from the analysis of the results: those cells which are fabricated at conditions of higher humidity tend to resist better the negative effect of aging. Thus, devices 
prepared at $0 \%$ and $30 \%$ humidity, show a clear splitting of the "red" and "blue" resistances upon degradation. In contrast, cells made at $40 \%$ and $50 \%$ humidity show less disparity between the two values of $R_{H F}$.

Similar conclusions can be extracted from the analysis of the frequency plots (Figure 5). In the studied frequency range, a distinct peak at around $10^{4}-10^{5} \mathrm{~Hz}$ is detected. Although the inverse of the corresponding frequency signal cannot be considered a real carrier lifetime, its time scale and its behaviour for different architectures and Fermi level positions strongly suggest that it is related with the recombination rate of photogenerated carriers in the device. ${ }^{31-33}$ The comparison of the behaviour of this signal for fresh and aged devices reveals that whereas for the former the "lifetime" is basically the same for red and blue light illuminations, the positions of the peaks for the latter are significantly different. Furthermore, the splitting of the red and blue signals tends to be more pronounced for the devices fabricated at lower humidity conditions.
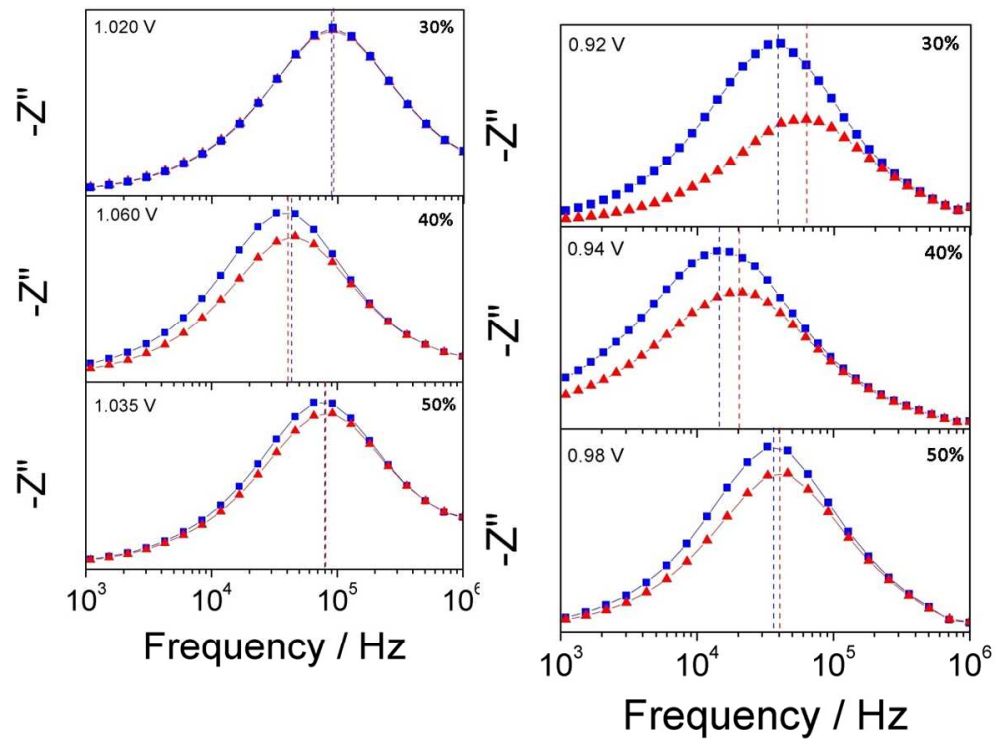

Figure 5. Imaginary part of the impedance in the $10^{6}-10^{3} \mathrm{~Hz}$ frequency range for fresh (left) and aged (right) $\mathrm{MAPbI}_{3}$ perovskite solar cells. Data obtained under red and blue light illumination are shown. The open-circuit photopotentials generated by the illumination are indicated in the graphs.

The robustness of the prepared devices is also confirmed when the capacitance extracted from impedance is analysed (Figure S5). Results previously reported for devices fabricated by a standard recipe at dry glovebox conditions ${ }^{13}$ showed the appearance after aging of an additional capacitive process, evidenced by a distortion of the high frequency arc and the disappearance of the mid-frequency plateau. Interestingly, these features are not observed for the devices fabricated at ambient humid conditions. 


\section{CONCLUSIONS}

Ambient water, when considered a Lewis donor additive and when incorporated into the preparation of $\mathrm{CH}_{3} \mathrm{NH}_{3} \mathrm{PbI}_{3}$-based perovskite solar cells, is found to have a positive effect on the stability of the fabricated devices when exposed to humid air. Optical absorption data show an increase of the light harvesting capability of the perovskite films which could be related to the enhancement of the short-circuit photocurrent after moisture exposure. XPS analysis reveal the presence of small amounts of water, in the form of coordinating molecules around the $\mathrm{Pb}$ cations. Based on this observation we tentatively attribute the robustness of the perovskite films to the presence of these molecules, which prevent the formation of additional hydrates that trigger the degradation mechanism.

On the other hand, degradation produces an acceleration of recombination, evidenced by a small deterioration of the open-circuit potential and the increase of the recombination rate. Aging also leads to a different impedance response under different optical penetrations of the bias light. This difference is found to be larger for devices prepared at conditions of lower humidity. This work highlights important effects to understand perovskite degradation processes and shows how a "homeopathic" strategy based on a preventive addition of water could be a promising way to struggling against it.

\section{ACKNOWLEDGMENT}

We thank Junta de Andalucía for financial support via grant FQM 1851 and FQM 2310, Ministerio de Economía y Competitividad of Spain under grants MAT2013-47192-C3-3-R and MAT2016-76892-C3-2-R and Red de Excelencia "Emerging photovoltaic Technologies". We also thank "Servicio de Microscopía Electrónica de la Universidad Pablo de Olavide" and the financial support from Generalitat Valenciana under DISOLAR2 (PROMETEOII/2014/020). A. G. would like to thank the Spanish Ministerio de Economía y Competitividad for a Ramón y Cajal Fellowship (RYC-2014-16809).

\section{References}

(1) Yang, W. S.; Park, B.-W.; Jung, E. H.; Jeon, N. J.; Kim, Y. C.; Lee, D. U.; Shin, S. S.; Seo, J.; Kim, E. K.; Noh, J. H.; et al. Iodide Management in Formamidinium-Lead-Halide-based Perovskite Layers for Efficient Solar Cells. Science 2017, 356 (6345), 1376-1379.

(2) Xing, G.; Mathews, N.; Sun, S.; Lim, S. S.; Lam, Y. M.; Grätzel, M.; Mhaisalkar, S.; Sum, T. C. Long-Range Balanced Electron- and Hole-Transport Lengths in Organic-Inorganic CH3NH3PbI3. Science 2013, 342 (6156), 344-347.

(3) Stranks, S. D.; Eperon, G. E.; Grancini, G.; Menelaou, C.; Alcocer, M. J. P.; Leijtens, T.; Herz, L. M.; Petrozza, A.; Snaith, H. J. Electron-Hole Diffusion Lengths Exceeding 1 
Micrometer in an Organometal Trihalide Perovskite Absorber. Science 2013, 342 (6156), 341-344.

(4) Tress, W.; Marinova, N.; Inganäs, O.; Nazeeruddin, M. K.; Zakeeruddin, S. M.; Graetzel, M. Predicting the Open-Circuit Voltage of CH3NH3PbI3 Perovskite Solar Cells Using Electroluminescence and Photovoltaic Quantum Efficiency Spectra: The Role of Radiative and Non-Radiative Recombination. Adv. Energy Mater. 2015, 5 (3), n/a-n/a.

(5) Tress, W. Perovskite Solar Cells on the Way to Their Radiative Efficiency Limit - Insights Into a Success Story of High Open-Circuit Voltage and Low Recombination. Adv. Energy Mater. 2017, 7 (14).

(6) Wang, Z.; Shi, Z.; Li, T.; Chen, Y.; Huang, W. Stability of Perovskite Solar Cells: A Prospective on the Substitution of the A Cation and X Anion. Angew. Chem. Int. Ed. 2017, 56 (5), 1190-1212.

(7) Tiep, N. H.; Ku, Z.; Fan, H. J. Recent Advances in Improving the Stability of Perovskite Solar Cells. Adv. Energy Mater. 2016, 6 (3), 1501420.

(8) Leguy, A. M. A.; Hu, Y.; Campoy-Quiles, M.; Alonso, M. I.; Weber, O. J.; Azarhoosh, P.; van Schilfgaarde, M.; Weller, M. T.; Bein, T.; Nelson, J.; et al. Reversible Hydration of CH3NH3PbI3 in Films, Single Crystals, and Solar Cells. Chem. Mater. 2015, 27 (9), 33973407.

(9) Yang, J.; Siempelkamp, B. D.; Liu, D.; Kelly, T. L. Investigation of CH3NH3PbI3 Degradation Rates and Mechanisms in Controlled Humidity Environments Using in Situ Techniques. ACS Nano 2015, 9 (2), 1955-1963.

(10) Frost, J. M.; Butler, K. T.; Brivio, F.; Hendon, C. H.; van Schilfgaarde, M.; Walsh, A. Atomistic Origins of High-Performance in Hybrid Halide Perovskite Solar Cells. Nano Lett. 2014, 14 (5), 2584-2590.

(11) Aranda, C.; Cristobal, C.; Shooshtari, L.; Li, C.; Huettner, S.; Guerrero, A. Formation Criteria of High Efficiency Perovskite Solar Cells under Ambient Conditions. Sustain. Energy Fuels 2017, 1 (3), 540-547.

(12) Li, D.; Bretschneider, S. A.; Bergmann, V. W.; Hermes, I. M.; Mars, J.; Klasen, A.; Lu, H.; Tremel, W.; Mezger, M.; Butt, H.-J.; et al. Humidity-Induced Grain Boundaries in MAPbI3 Perovskite Films. J. Phys. Chem. C 2016, 120 (12), 6363-6368.

(13) Salado, M.; Contreras-Bernal, L.; Caliò, L.; Todinova, A.; López-Santos, C.; Ahmad, S.; Borras, A.; Idígoras, J.; Anta, J. A. Impact of Moisture on Efficiency-Determining Electronic Processes in Perovskite Solar Cells. J Mater Chem A 2017, 5 (22), 10917-10927.

(14) Contreras-Bernal, L.; Salado, M.; Todinova, A.; Calio, L.; Ahmad, S.; Idígoras, J.; Anta, J. A. Origin and Whereabouts of Recombination in Perovskite Solar Cells. J. Phys. Chem. C 2017, 121 (18), 9705-9713.

(15) Correa-Baena, J.-P.; Turren-Cruz, S.-H.; Tress, W.; Hagfeldt, A.; Aranda, C.; Shooshtari, L.; Bisquert, J.; Guerrero, A. Changes from Bulk to Surface Recombination Mechanisms between Pristine and Cycled Perovskite Solar Cells. ACS Energy Lett. 2017, 2 (3), 681-688.

(16) Reese, M. O.; Gevorgyan, S. A.; Jørgensen, M.; Bundgaard, E.; Kurtz, S. R.; Ginley, D. S.; Olson, D. C.; Lloyd, M. T.; Morvillo, P.; Katz, E. A.; et al. Consensus Stability Testing Protocols for Organic Photovoltaic Materials and Devices. Sol. Energy Mater. Sol. Cells 2011, 95 (5), 1253-1267.

(17) Rahimnejad, S.; Kovalenko, A.; Forés, S. M.; Aranda, C.; Guerrero, A. Coordination Chemistry Dictates the Structural Defects in Lead Halide Perovskites. Chemphyschem Eur. J. Chem. Phys. Phys. Chem. 2016, 17 (18), 2795-2798. 
(18) Roose, B.; Ummadisingu, A.; Correa-Baena, J.-P.; Saliba, M.; Hagfeldt, A.; Graetzel, M.; Steiner, U.; Abate, A. Spontaneous Crystal Coalescence Enables Highly Efficient Perovskite Solar Cells. Nano Energy 2017, 39 (Supplement C), 24-29.

(19) Pham, N. D.; Tiong, V. T.; Yao, D.; Martens, W.; Guerrero, A.; Bisquert, J.; Wang, H. Guanidinium Thiocyanate Selective Ostwald Ripening Induced Large Grain for High Performance Perovskite Solar Cells. Nano Energy 2017, 41 (Supplement C), 476-487.

(20) Biesinger, M. C.; Lau, L. W. M.; Gerson, A. R.; Smart, R. S. C. Resolving Surface Chemical States in XPS Analysis of First Row Transition Metals, Oxides and Hydroxides: Sc, Ti, V, Cu and Zn. Appl. Surf. Sci. 2010, 257 (3), 887-898.

(21) NIST X-ray Photoelectron Spectroscopy (XPS) Database, Version 3.5 https://srdata.nist.gov/xps/ (accessed Oct 9, 2017).

(22) Schumacher, B.; Plzak, V.; Cai, J.; Behm, R. J. Reproducibility of Highly Active Au/TiO2 Catalyst Preparation and Conditioning. Catal. Lett. 2005, 101 (3-4), 215-224.

(23) Liu, H.; Yang, W.; Ma, Y.; Cao, Y.; Yao, J.; Zhang, J.; Hu, T. Synthesis and Characterization of Titania Prepared by Using a Photoassisted Sol-Gel Method. Langmuir 2003, 19 (7), 3001-3005.

(24) Zubavichus, Y. V.; Slovokhotov, Y. L.; Nazeeruddin, M. K.; Zakeeruddin, S. M.; Grätzel, M.; Shklover, V. Structural Characterization of Solar Cell Prototypes Based on Nanocrystalline TiO2 Anatase Sensitized with Ru Complexes. X-Ray Diffraction, XPS, and XAFS Spectroscopy Study. Chem. Mater. 2002, 14 (8), 3556-3563.

(25) Pockett, A.; Eperon, G. E.; Sakai, N.; Snaith, H. J.; Peter, L. M.; Cameron, P. J. Microseconds, Milliseconds and Seconds: Deconvoluting the Dynamic Behaviour of Planar Perovskite Solar Cells. Phys. Chem. Chem. Phys. 2017, 19 (8), 5959-5970.

(26) Zarazua, I.; Han, G.; Boix, P. P.; Mhaisalkar, S.; Fabregat-Santiago, F.; Mora-Seró, I.; Bisquert, J.; Garcia-Belmonte, G. Surface Recombination and Collection Efficiency in Perovskite Solar Cells from Impedance Analysis. J. Phys. Chem. Lett. 2016, 7 (24), 51055113.

(27) Guerrero, A.; Garcia-Belmonte, G.; Mora-Sero, I.; Bisquert, J.; Kang, Y. S.; Jacobsson, T. J.; Correa-Baena, J.-P.; Hagfeldt, A. Properties of Contact and Bulk Impedances in Hybrid Lead Halide Perovskite Solar Cells Including Inductive Loop Elements. J. Phys. Chem. C 2016, 120 (15), 8023-8032.

(28) Correa-Baena, J.-P.; Anaya, M.; Lozano, G.; Tress, W.; Domanski, K.; Saliba, M.; Matsui, T.; Jacobsson, T. J.; Calvo, M. E.; Abate, A.; et al. Unbroken Perovskite: Interplay of Morphology, Electro-Optical Properties, and Ionic Movement. Adv. Mater. 2016, n/a-n/a.

(29) Contreras, L.; Idígoras, J.; Todinova, A.; Salado, M.; Kazim, S.; Ahmad, S.; Anta, J. A. Specific Cation Interactions as the Cause of Slow Dynamics and Hysteresis in Dye and Perovskite Solar Cells: A Small-Perturbation Study. Phys. Chem. Chem. Phys. 2016, 18 (45), 31033-31042.

(30) Juarez-Perez, E. J.; Wußler, M.; Fabregat-Santiago, F.; Lakus-Wollny, K.; Mankel, E.; Mayer, T.; Jaegermann, W.; Mora-Sero, I. Role of the Selective Contacts in the Performance of Lead Halide Perovskite Solar Cells. J. Phys. Chem. Lett. 2014, 5 (4), 680685.

(31) Todinova, A.; Idígoras, J.; Salado, M.; Kazim, S.; Anta, J. A. Universal Features of Electron Dynamics in Solar Cells with TiO2 Contact: From Dye Solar Cells to Perovskite Solar Cells. J. Phys. Chem. Lett. 2015, 6 (19), 3923-3930.

(32) Pascoe, A. R.; Duffy, N. W.; Scully, A. D.; Huang, F.; Cheng, Y.-B. Insights into Planar CH3NH3PbI3 Perovskite Solar Cells Using Impedance Spectroscopy. J. Phys. Chem. C 2015, 119 (9), 4444-4453. 
(33) Pydzińska, K.; Karolczak, J.; Kosta, I.; Tena-Zaera, R.; Todinova, A.; Idígoras, J.; Anta, J. A.; Ziółek, M. Determination of Interfacial Charge-Transfer Rate Constants in Perovskite Solar Cells. ChemSusChem 2016, n/a-n/a.

(34) Todinova, A.; Contreras-Bernal, L.; Salado, M.; Ahmad, S.; Morillo, N.; Idígoras, J.; Anta, J. A. Towards Universal Approach to the Analysis of Impedance Spectra of Perovskite Solar Cells. Equivalent Circuits and Empirical Analysis. ChemElectroChem.

(35) Bi, D.; Tress, W.; Dar, M. I.; Gao, P.; Luo, J.; Renevier, C.; Schenk, K.; Abate, A.; Giordano, F.; Baena, J.-P. C.; et al. Efficient Luminescent Solar Cells Based on Tailored Mixed-Cation Perovskites. Sci. Adv. 2016, 2 (1), e1501170.

(36) Leong, W. L.; Ooi, Z.-E.; Sabba, D.; Yi, C.; Zakeeruddin, S. M.; Graetzel, M.; Gordon, J. M.; Katz, E. A.; Mathews, N. Identifying Fundamental Limitations in Halide Perovskite Solar Cells. Adv. Mater. 2016, 28 (12), 2439-2445.

(37) Tress, W.; Yavari, M.; Domanski, K.; Yadav, P.; Niesen, B.; Baena, J. P. C.; Hagfeldt, A.; Graetzel, M. Interpretation and Evolution of Open-Circuit Voltage, Recombination, Ideality Factor and Subgap Defect States during Reversible Light-Soaking and Irreversible Degradation of Perovskite Solar Cells. Energy Environ. Sci. 2017. 